\title{
Upaya Teknis Rehabilitasi TPA Sampah Kopi Luhur dengan Sistem Lahan Urug Terkendali
}

\author{
Nendia Nur Isni, Andi Sungkowo, dan Ika Wahyuning Widiarti \\ Jurusan Teknik Lingkungan, Fakultas Teknologi Mineral, UPN “Veteran” Yogyakarta \\ JL. SWK 104 Condong Catur, Depok, Sleman, Yogyakarta \\ E-mail korespondensi: ika.widiarti@upnyk.ac.id
}

\begin{abstract}
ABSTRAK
Penilaian indeks risiko lingkungan TPA Sampah Kopi Luhur menghasilkan nilai 575,3536, tergolong kategori bahaya sedang, sehingga tindakan yang disarankan adalah meneruskan TPA dan melakukan rehabilitasi menjadi lahan urug terkendali secara bertahap. Penelitian ini bertujuan untuk merencanakan proses landfill mining pada timbunan sampah yang sudah tidak aktif dan merancang sistem lahan urug TPA dengan sistem controlled landfill. Metodologi dalam penelitian yaitu metode survey dan pemetaan serta pengukuran terhadap komposisi sampah. Penambangan lahan urug dan perancangan lahan urug baru menggunakan sistem controlled landfill mengacu pada Peraturan Menteri Pekerjaam Umum No.3/2013. Tujuan dari penelitian ini adalah untuk merancang proses landfill mining pada sel sampah yang sudah tidak aktif dan merancang lahan urug sampah dengan menggunakan sistem controlled landfill di TPA Sampah Kopi Luhur. Hasil penelitian menunjukkan bahwa kandungan sampah lama di TPA Sampah Kopi Luhur terdiri dari 9,09 \% Bahan Berbahaya Beracun (B3), 12,91 \% biodagredable dan 58\% non-biodegradable. Komposisi sampah tersebut menjadi acuan dalam melakukan landfill mining dan proses rehabilitasi TPA Sampah Kopi Luhur menjadi lahan urug terkendali diterapkan setelah melakukan landfill mining. Area lahan urug baru dengan sistem controlled landfill mempunyai panjang $198 \mathrm{~m}$ dan lebar 65, yang mempunyai 3 lapisan dengan ketebalan sampah $5 \mathrm{~m}$. Selain itu, lahan urug dilengkapi dengan fasilitas perlindungan lingkungan seperti lapisan dasar, sistem drainase, jaringan pengumpul lindi dan sistem pengendali gas. Penerapan sistem controlled landfill tersebut menjadikan lahan urug baru mempunyai umur pakai selama 6,6 tahun.
\end{abstract}

Kata Kunci : TPA Sampah Kopi Luhur, Controlled Landfill, Penambangan Lahan Urug

\begin{abstract}
The risk index value of Kopi Luhur Waste Landfill is 575.3536, classified as moderate hazard category and the suggested action is to continue the landfill and apply the rehabilitation into a controlled landfill system gradually. The purpose of this research are to de design the rehabilitation steps based on some measurement in Kopi Luhur Waste Landfill. The purpose of this research are to design the process of landfill mining in unactive landfill and to design a landfill with controlled landfill system. The methodology in the research are survey \& mapping method and measurement of waste composition. The landfill mining process and the controlled landfill system is designed based on The Minister of Public Works Regulation No.3/2013 and the existing condition of Kopi Luhur Waste Landfill. The result shows that Kopi Luhur Waste Landfill consists of 9.09\% hazardous waste, $12.91 \%$ biodegradable waste and 58\% non-biodegradable waste. The waste composition become a reference in conducting landfill mining and the rehabilitation process of Kopi Luhur Landfill into controlled landfill is applied after applying the landfill mining process. The new landfill land area with a controlled landfill system has a length of $198 \mathrm{~m}$ and $a$ width of 65, which has 3 layers with a thickness of $5 \mathrm{~m}$. The waste is spread into a thickness of 0.5 $m$, compressed by heavy equipment and then covered by a $20 \mathrm{~cm}$ daily overburden when the waste lift reaches 2.5 $m$. In addition, the landfill system is equipped with environmental protection facilities such as the base layer, drainage system, leachate collection network and gas control system. The implementation of the controlled landfill system make the new landfill has 6.6 years lifespan.
\end{abstract}

Keywords: Kopi Luhur Waste Landfill, Controlled Landfill, Landfill Mining 


\section{PENDAHULUAN}

Berdasarkan Badan Pusat Statistika Kota Cirebon, penduduk Kota Cirebon meningkat setiap tahunnya, dengan berbagai macam aktifitas di Kota Cirebon yang membuat produksi sampah yang dihasilkan semakin meningkat. Selama ini masih banyak warga Kota Cirebon yang tidak paham tentang pengelolaan sampah sehingga sampah yang dihasilkan pada akhirnya hanya sebatas pada pengumpulan sampah, pengangkutan sampah dan penumpukan sampah di tempat pembuangan akhir. TPA Sampah Kopi Luhur yang berada di Dusun Sumur Wuni, Kelurahan Argasunya, Kecamatan Harjamukti, Kota Cirebon merupakan TPA terbesar di Kota Cirebon dan sebagai tempat penyimpanan terakhir sampah yang berasal dari seluruh kecamatan yang ada di Kota Cirebon yaitu Kecamatan Harjamukti, Lemahwungkuk, Pekalipan, Kesambi dan Kejaksan. Berdasarkan data dari pengelola, TPA Kopi Luhur sudah beroperasi sejak tahun 1998 dengan luas total lahan sebesar 13 Ha yang terdiri dari lahan yang beroperasi untuk penimbunan seluas $9 \mathrm{Ha}$ dan lahan kosong seluas $4 \mathrm{Ha}$. Volume yang diterima dari seluruh wilayah Kota Cirebon sebanyak kurang lebih $550 \mathrm{~m}^{3}$ sampah. TPA Kopi Luhur pada awal perencanaannya dibangun untuk menggunakan sistem controlled landfill, tetapi pada pelaksanaan selama TPA ini beroperasi hanya menerapkan sistem open dumping.

Berdasarkan definisi pada peraturan Menteri Pekerjaan Umum No.3 Tahun 2013, metode open dumping merupakan proses penimbunan sampah di TPA tanpa melalui proses pemadatan dan penutupan secara berkala, metode controlled landfill adalah metode pengurugan di areal pengurugan sampah, dengan cara dipadatkan dan ditutup dengan tanah penutup sekurang-kurangnya setiap tujuh hari. Metode ini merupakan metode yang bersifat antara, sebelum mampu menerapkan metode lahan urug saniter. Kelebihan dalam menerapkan sistem controlled landfill yaitu dampak terhadap lingkungan dapat diperkecil, lahan dapat digunakan kembali setelah selesai dipakai dan estetika lingkungan cukup baik. Sedangkan, kekurangannya adalah operasi lapangan relatif lebih sulit, biaya investasi cukup besar dan memerlukan personalia lapangan yang cukup terlatih, sedangkan metode sanitary landfill adalah metode pengurugan di area pengurugan sampah yang disiapkan dan dioperasikan secara sistematis, dengan penyebaran dan pemadatan sampah pada area pengurugan serta penutupan sampah setiap hari.

Pelaksanaan sistem open dumping di lokasi penelitian dapat terlihat dari keadaan timbunan sampah di TPA yang tidak ditutupi oleh tanah penutup dan lapisan kedap air secara rutin. Tanah penutup dan lapisan kedap air berfungsi untuk mencegah rembesan air lindi yang terbentuk di dasar TPA ke dalam lapisan tanah, sehingga lapisan ini harus dibentuk di seluruh permukaan dalam TPA. Tidak tersedianya tanah penutup dan lapisan kedap air, menyebabkan saat musim hujan air lindi tercecer sampai ke badan jalan truk pengangkut sampah, karena tidak adanya saluran drainase untuk mengendalikan aliran air. Sistem drainase tersebut seharusnya berfungsi untuk mengendalikan aliran limpasan dengan tujuan untuk memperkecil aliran yang masuk ke timbunan sampah, karena air hujan merupakan faktor utama terhadap debit lindi yang dihasilkan. Selain itu, TPA Kopi Luhur tidak melakukan proses pengolahan air lindi, padahal air lindi terus dihasilkan dari TPA yang salah satunya berasal dari hasil dekomposisi sampah itu sendiri. Menurut Damanhuri dan Padmi (2016), komposisi zat kimia dari air lindi dipengaruhi pada beberapa hal yaitu karakteristk dan komposisi sampah, jenis tanah penutup landfill, musim pergantian, $\mathrm{pH}$ dan kelembaban dan umur timbunan (usia landfill). Oleh karenanya, pengaruh air lindi sangat besar untuk lingkungan sekitar. Air lindi yang tidak dikelola dapat mengganggu kegiatan operasional di TPA salah satunya rembesan air lindi yang menyebabkan jalan berlumpur sehingga 
kesulitan untuk mobilisasi alat berat. Air lindi yang tidak dikelola juga dapat menimbulkan potensi pencemaran terhadap air tanah dan tanah, sehingga secara tidak langsung dapat merusak habitat kehidupan flora dan fauna di daerah penelitian. TPA Sampah Kopi Luhur tidak mempunyai unit pengendalian gas metana. Gas metana merupakan gas terbesar yang dihasilkan dari kegiatan TPA sehingga perlu dikelola, karena dengan adanya gas metana yang dihasilkan dari TPA dapat menyumbang konsentrasi gas rumah kaca di atmosfer dan adanya potensi bahaya ledakan yang berasal dari gas metana yang sifatnya mudah meledak. Komposisi terbesar dari gas yang dihasilkan adalah gas metana dan karbon dioksida. Selain gas metana, gas yang timbul di TPA adalah gas $\mathrm{H}_{2} \mathrm{~S}$. Gas $\mathrm{H}_{2} \mathrm{~S}$ dengan konsentrasi $500 \mathrm{ppm}$, dapat menimbulkan kematian, edema pulmonari dan asfiksian. $\mathrm{H}_{2} \mathrm{~S}$ digolongkan asfiksian karena efek utamanya adalah melumpuhkan pusat pernapasan, sehingga kematian disebabkan oleh terhentinya pernapasan (Soemirat, 2009 dalam Andhika, 2015). Berdasarkan permasalahan tersebut sehingga diperlukan adanya rehabilitasi TPA Sampah Kopi Luhur dengan tujuan mengurangi pencemaran yang ada dengan melakukan penyaringan terhadap komposisi sampah yang ada.

Peraturan Menteri Pekerjaan Umum RI No.3/2013 menjelaskan bahwa rehabilitasi TPA dapat diaplikasikan apabila memenuhi beberapa ketentuan, antara lain telah menimbulkan masalah lingkungan, sesuai dengan penilaian indeks risiko lingkungan, kondisi TPA masih memungkinkan untuk direhabilitasi baik melalui proses landfill mining terlebih dahulu atau digunakan kembali sebagai area pengurugan sampah, TPA memiliki luas lebih dari $2 \mathrm{Ha}$, pengelola dan pemerintah daerah mampu untuk mengoperasikan TPA secara lahan urug terkendali atau lahan urug saniter dan adanya ketersediaan rencana dan desain terhadap penggunaan kembali lahan TPA sebagai area pengurug sampah. Berkaitan dengan ketentuan tersebut, permasalahan yang ada di TPA Sampah Kopi Luhur dilakukan penelitian tentang evaluasi kualitas lingkungan menggunakan penilaian indeks risiko lingkungan yang mengacu pada Menteri Pekerjaan Umum RI No.3/2013.

Penelitian sebelumnya telah menghasilkan nilai indeks risiko lingkungan TPA Sampah Kopi Luhur sebesar 575, 3.536 yang tergolong pada ketegori bahaya sedang, sehingga tindakan yang disarankan adalah dilakukan rehabilitasi menjadi lahan urug terkendali secara bertahap (Isni, 2019). Sehingga kondisi di TPA Sampah Kopi Luhur dan ketentuan pada Peraturan Menteri Pekerjaan Umum No.3 Tahun 2013, TPA perlu dilakukan proses rehabilitasi secara bertahap. Tujuan dari penelitian ini adalah untuk merancang proses landfill mining pada sel sampah yang sudah tidak aktif dan merancang lahan urug sampah dengan menggunakan sistem controlled landfill di TPA Sampah Kopi Luhur.

\section{METODE PENELITIAN}

Penelitian dilakukan dengan cara melakukan pengamatan dan pengukuran secara langsung di lapangan untuk mendapatkan data faktual, mengolah data lapangan yang telah didapat dan melakukan analisa terhadap data yang ada. Metode yang digunakan adalah metode survei dan pemetaan lapangan dan pengukuran terhadap komposisi sampah. Metode survey dan pemetaan lapangan bertujuan untuk megetahui asumsi awal permasalahan di TPA Sampah Kopi Luhur dan mencari data rona lingkungan hidup seperti iklim, satuan batuan, jenis tanah dan bentuklahan. Pengukuran terhadap komposisi sampah bertujuan untuk mengetahui jenis sampah yang ditimbun di TPA Sampah Kopi Luhur dan sebagai arahan untuk melakukan penambangan lahan urug (landfill mining). Pengukuran tersebut meliputi fraksi sampah bio-degradable dan kandungan B3 dalam sampah. Pengukuran terhadap kandungan B3 dalam 
sampah dan fraksi sampah biodegradable dilakukan pada 3 titik dengan menggunakan box, kemudian dilakukan pengukuran terhadap massa dan volume box sehingga didapatkan nilai densitasnya.

Data mengenai komposisi sampah yang sudah didapat melalui pengukuran di lapangan secara langsung, menjadi acuan dalam melakukan landfill mining. Landfill mining di TPA Sampah Kopi Luhur dilakukan pada timbunan sampah yang sudah tidak aktif lagi. Proses yang dilakukan dengan melakukan penggalian untuk mengangkat dan memindahkan kandungan dari sel lahan urug dan dilakukan penyaringan secara manual untuk memisahkan kandungan kompos, plastik, logam, kertas dsb. Penerapan sistem controlled landfill di TPA Sampah Kopi Luhur, diaplikasikan dengan menerapkan cara pengurugan sampah yang sesuai dan dilengkapi dengan fasilitas perlindungan seperti lapisan dasar, sistem drainase, jaringan pengumpul lindi dan sistem pengendali gas. Proses landfill mining, cara pengurugan sampah, rancangan lahan urug baru dan fasilitas perlindungan lingkungan mengacu pada Peraturan Menteri Pekerjaan Umum RI No.3/2013.

\section{HASIL DAN PEMBAHASAN}

Berdasarkan nilai indeks risiko lingkungan menunjukkan TPA Sampah Kopi Luhur perlu dilakukan rehabilitasi menjadi lahan urug terkendali secara bertahap. Selain itu dicantumkan pada Undang-Undang No.18 Tahun 2008, menyatakan bahwa kota-kota besar di Indonesia harus menerapkan lahan urug saniter atau sanitary landfill dan Kota Cirebon merupakan salah satu kota besar di Indonesia. Selain itu, pada Peraturan Daerah Kota Cirebon tentang RT/RW Kota Cirebon tahun 2011-2031 disebutkan bahwa TPA Sampah Kopi Luhur diperuntukkan sebagai TPA dengan sistem sanitary landfill. Tetapi, berdasarkan pengukuran dan pengamatan langsung di lapangan tidak memungkinkan diterapkan sistem sanitary landfill. Hal tersebut dikarenakan dalam perubahan sistem baru terutama sanitary landfill membutuhkan investasi yang sangat besar. Selain itu cara pengurugan sampah di TPA Sampah Kopi Luhur belum sesuai, fasilitas perlindungan yang tidak memadai di TPA, belum adanya dukungan dari Dinas Lingkungan Hidup dsb. Sehingga dalam memperbaiki permasalahan lingkungan perlu diterapkan cara pengurugan baru dari open dumping menjadi controlled landfill secara berkala.

Kondisi sel sampah lama di TPA Sampah Kopi Luhur saat ini memiliki jumlah volume $\pm 89.842,5 \mathrm{~m}^{3}$. Sampah di timbunan sampah dilakukan penambangan dan dipilah untuk memisahkan antara sampah biodegradable, sampah B3 dan sampah yang tidak dapat didaur ulang. Kandungan sampah lama tersebut diasumsikan berdasarkan pengukuran di lapangan yang terdiri dari 9,09\% B3, 12,91\% biodagredable dan 78\% sampah plastik (non-biodegradable). Sebanyak 20\% sampah plastik dari komposisi $78 \%$ sampah plastik yang ada di TPA diasumsikan masih mempunyai nilai untuk dimanfaatkan kembali. Sehingga hanya 58\% sampah non-biodegredable yang akan diurug kembali. Berdasarkan pengukuran tersebut, diketahui sampah maksimum yang akan menjadi residu adalah $67,09 \%$. Nilai tersebut adalah jumlah dari sampah B3 sebesar 9,09\% dan 58\% sampah plastik (non-biodegradable).

Proses rehabilitasi TPA diaplikasikan dengan diawali proses penambangan lahan urug kemudian merancang lahan urug yang baru dengan sistem controlled landfill. Penambangan lahan urug diaplikasikan saat ketersediaan lahan penimbunan sampah tergolong minim, sehingga memanfaatkan lahan penimbunan sampah yang lama. Pelaksanaannya dilakukan dengan cara penggalian dari atas, yaitu cara yang penambangan paling aman karena alat berat terbebas dari jebakan gas dan pekerjaan galian 


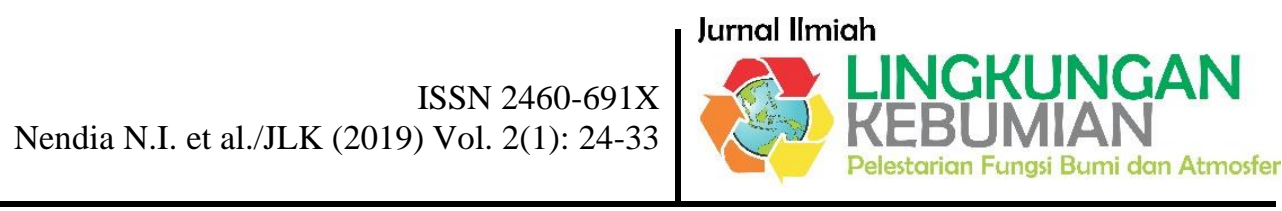

bebas dari pekerjaan pengamanan tebing. Proses penambangan dilakukan pada lokasi yang searah dengan tiupan angin dominan di daerah penelitian yaitu arah timur laut. Hal tersebut bertujuan agar saat operasi alat berat operator tidak menghisap gas yang terjebak di dalam timbunan sampah. Timbunan sampah yang dilakukan penambangan ditunjukkan pada Gambar 1, karena timbunan sampah tersebut sudah tidak aktif lagi sehingga diasumsikan proses penguraian sampah sudah terjadi. Pelaksanaannya dilakukan dengan cara penggalian dari atas, yaitu cara yang penambangan paling aman karena alat berat terbebas dari jebakan gas dan pekerjaan galian bebas dari pekerjaan pengamanan tebing. Proses penambangan dilakukan pada lokasi yang searah dengan tiupan angin dominan di daerah penelitian yaitu arah timur laut. Hal tersebut bertujuan agar saat operasi alat berat operator tidak menghisap gas yang terjebak di dalam timbunan sampah. Akhir dari galian penambangan TPA datar dapat berupa lokasi galian pertama saat awal pengoperasian TPA. Sehingga lokasi penambangan dapat digunakan kembali sebagai TPA baru. Proses penambangan dapat dilihat pada Gambar 2.

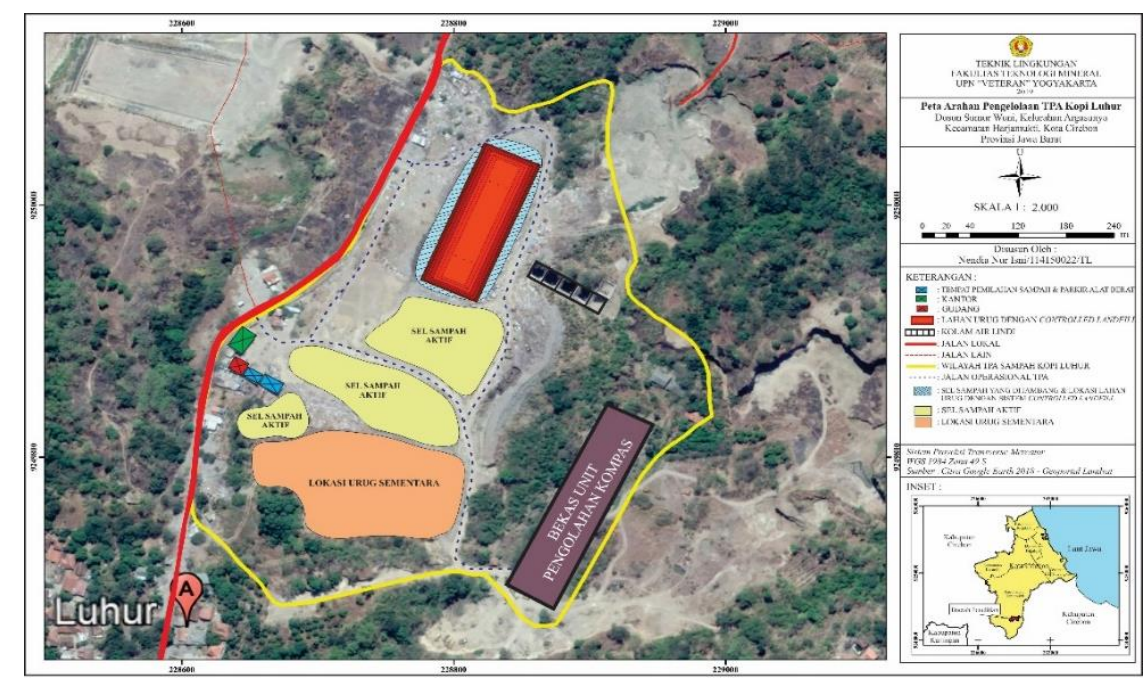

Gambar 1. Arahan Pengelolaan TPA Sampah Kopi Luhur

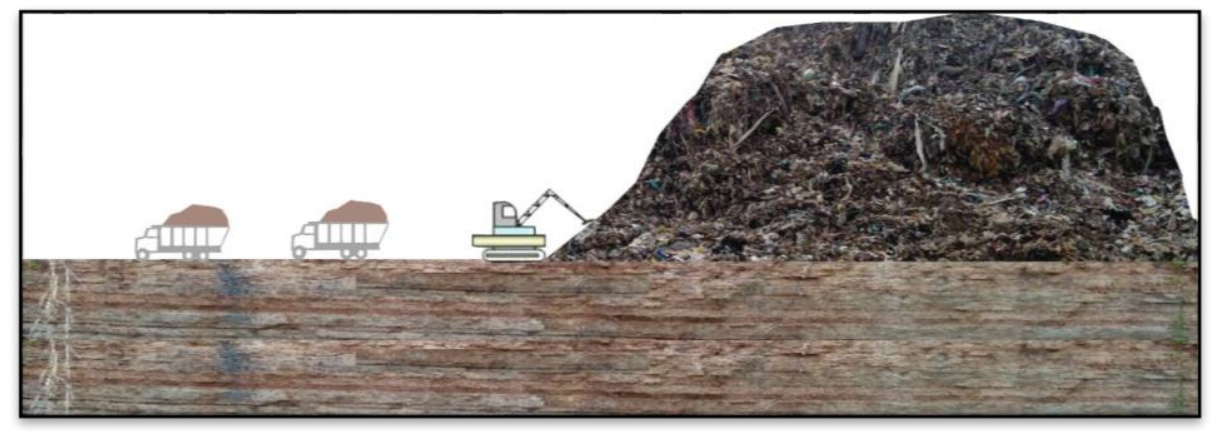

Gambar 2. Proses Penambangan Lahan Urug

Proses landfill mining yang telah dilakukan sebelumnya bertujuan untuk mengurangi jumlah sampah yang akan diurug kembali. Pembuatan lahan urug sampah dengan sistem controlled landfill di TPA Sampah Kopi Luhur adalah dengan memperbaiki cara pengurugan sampah pada timbunan dan merancang fasilitas perlindungan lingkungan. Penentuan kapasitas lahan urug sampah dengan sistem 
controlled landfill diketahui melalui perhitungan volume bahan urug maksimal. Data yang dibutuhkan untuk menghitung volume bahan urug maksimal seperti panjang dan lebar rancangan timbunan baru, kedalaman galian, densitas sampah, timbulan sampah per hari dan volume residu hasil landfill mining. Area timbunan sampah dengan sistem controlled landfill yang akan diperbaiki mempunyai panjang 198 $\mathrm{m}$ dan lebar $65 \mathrm{~m}$. Timbunan sampah yang dirancang mempunyai 3 lapisan dengan ketebalan sampah 5 $\mathrm{m}$. Setiap sampah disebar sampai ketebalan $0,5 \mathrm{~m}$, dipadatkan oleh alat berat kemudian ditutup oleh tanah penutup harian setebal $20 \mathrm{~cm}$ saat lift sampah mencapai 2,5 m. Tanah penutup harian pada sistem controlled landfill dilakukan setiap 7 hari sekali. Penerapan landfill mining dan pengurugan sampah dengan sistem controlled landfill tersebut maka ketinggian maksimum timbunan sampah yang direncanakan adalah $15 \mathrm{~m}$ dan volume bahan urug maksimal setelah dikurangi volume sampah hasil proses landfill mining adalah $197.760 \mathrm{~m}^{3}$, serta umur pakai lahan urug tersebut menjadi 6,6 tahun.

Lahan urug dengan sistem controlled landfill juga dilengkapi dengan fasilitas perlindungan lingkungan, yaitu :

\section{Lapisan Dasar (Liner)}

Berdasarkan Peraturan Menteri Pekerjaan Umum No.3 Tahun 2013, lapisan dasar sebuah lahan urug terdiri dari 3 komponen utama yaitu :

a. Lapisan kedap, yaitu lapisan paling bawah dari sebuah lahan urug sampah, berfungsi sebagai penahan resapan lindi ke air tanah dirancang dengan ketebalan lapisan $80 \mathrm{~cm}$. Lapisan terbawah dari sistem urug adalah tanah setempat yang dipadatkan dan bahan campuran lain yang kedap air. Bahan campuran yang digunakan dalam penelitian ini adalah bahan alami yaitu tanah liat (clay). Kriteria pemilihan tanah liat karena mempunyai permeabilitas yang rendah dan mempunyai kapasitas besar dalam mengabsorbsi kontaminan.

b. Lapisan media drainase, yaitu lapisan yang berisi pasir/kerikil, atau geosintetis, yang berfungsi sebagai media mengalirkan lindi menuju saluran pengumpul (Damanhuri \& Tri Padmi, 2016). Jenis media drainase yang digunakan dalam rancangan adalah lapisan permeabel berupa kerikil-kerikil berdiameter $5-7 \mathrm{~cm}$. dengan ketebalan lapisan $50 \mathrm{~cm}$.

c. Lapisan media pelindung, yaitu lapisan yang berfungsi sebagai pelindung lapisan kedap dari pelintasan kendaraan dan gangguan lainnya. Lapisan media pelindung yang digunakan adalah geotekstil. Geotekstil adalah salah satu jenis geosintetis yang dibuat tidak kedap air, yang sifat utamanya sebagai filter yaitu menyaring materi-materi tersuspensi yang terkandung dalam air lindi serta lapisan ini mempunyai fungsi untuk melindungi lapisan geomembran.

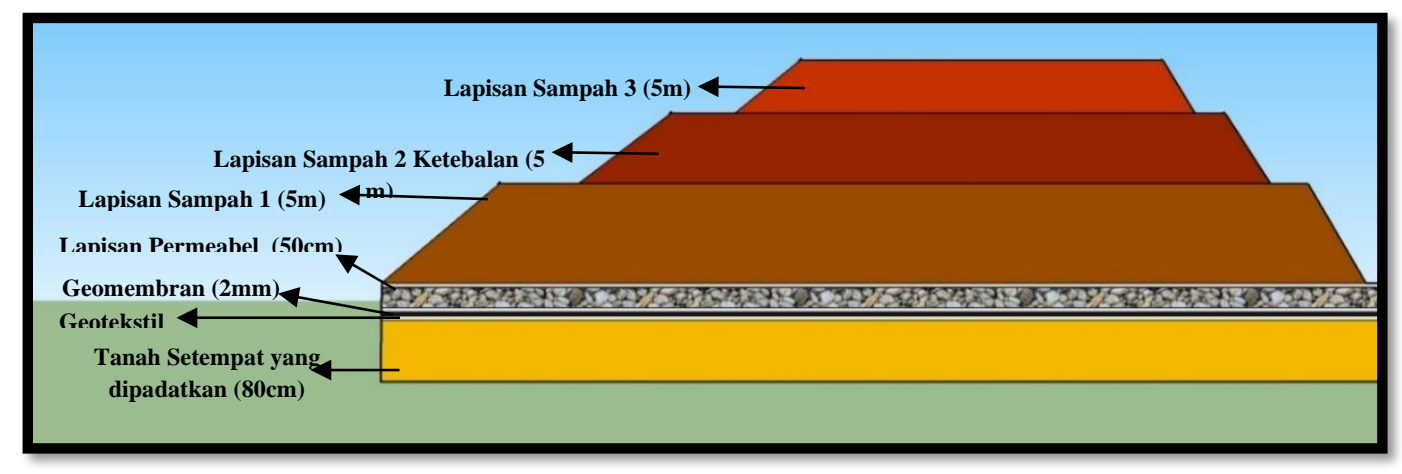

Gambar 3. Rancangan Lapisan Kedap Air di TPA Sampah Kopi Luhur 
2. Drainase Pengumpul Lindi

Sistem drainase lindi mempunyai peranan penting agar tidak terjadi akumulasi air lindi di sekitar lahan urug, yang menambah potensi perkolasi lindi ke dalam air tanah. Drainase yang dibuat berfungsi untuk mengatur pipa pengumpul lindi primer dan pipa pengumpul sekunder. Kemiringan pipa pengumpul lindi dibuat miring menuju Instalasi Pengolahan Lindi sebesar 2\%. Posisi pipa yang dibuat miring mengarah menuju IPAL bertujuan agar air lindi yang dihasilkan dari timbunan sampah mengalir melalui pipa menuju IPAL karena adanya gravitasi.

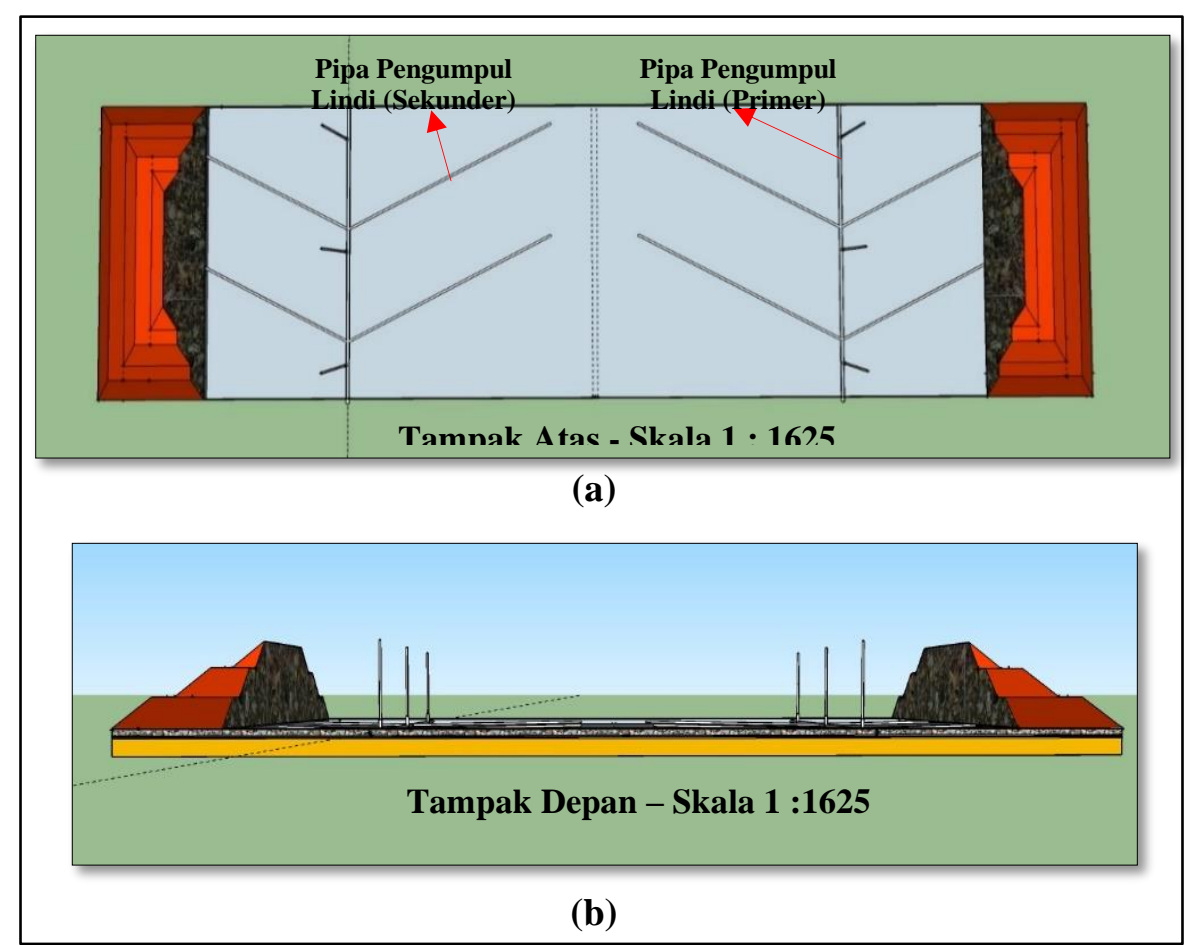

Gambar 4. Rancangan Sistem Drainase Pengumpul Lindi di TPA Sampah Kopi Luhur (a) Tampak Atas ; (b) Tampak Depan.

\section{Jaringan Pengumpul Lindi dan Kolam Penampung Lindi}

Sistem pengumpul lindi merupakan salah satu bagian terintegrasi dari rancangan. Sistem pengumpul lindi ini dibutuhkan oleh sebuah lahan urug dan berhubungan dengan struktur impermeabel dan pipa yang ditempatkan dalam urugan tersebut untuk mengumpulkan air lindi. Pipa pengumpul lindi dirancang mengacu pada Peraturan Menteri Pekerjaan Umum No.3 Tahun 2013. Diameter minimum pipa pengumpul lindi yaitu $20 \mathrm{~cm}$, diameter pipa yang digunakan dalam rancangan adalah $30 \mathrm{~cm}$. Pipa pengumpul lindi dibuat lubang-lubang kecil berdiameter $1,5 \mathrm{~cm}$ dengan jarak tiap lubangnya $5 \mathrm{~cm}$ (Gambar 5) Hasil uji kualitas air lindi masih belum sesuai dengan baku mutu sehingga diperlukan adanya pengkajian dan desain khusus untuk membangun IPAL yang sesuai. Pipa pengumpul lindi primer, Pipa pengumpul lindi sekunder dan pipa pengendali gas dipasang saling berkaitan satu sama lain (Gambar 6). 


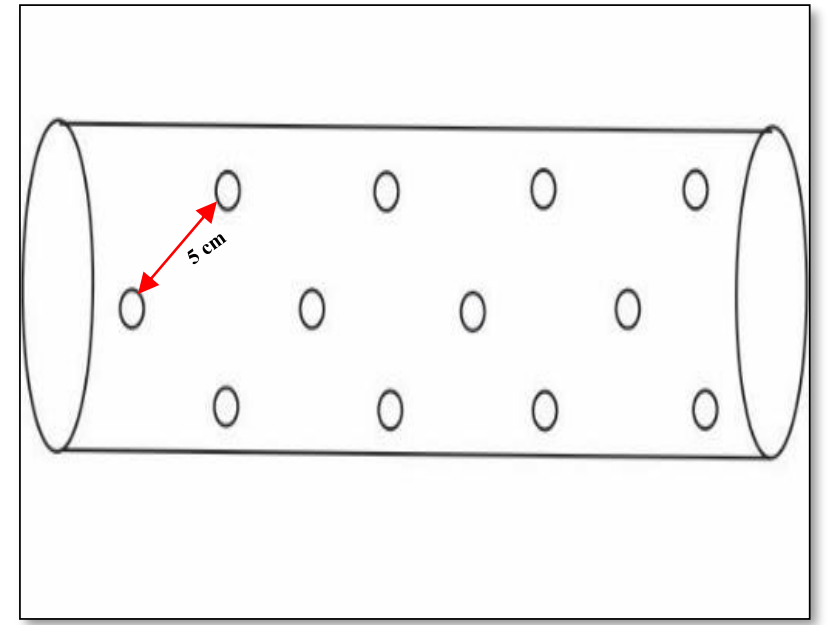

Gambar 5. Rancangan Pipa Pengumpul Air Lindi di TPA Sampah Kopi Luhur

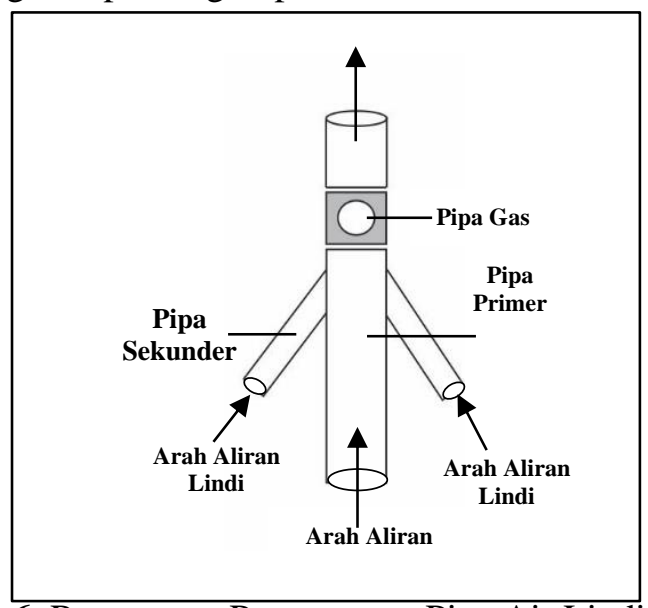

Gambar 6. Rancangan Penempatan Pipa Air Lindi dan Pipa Gas

\section{Tanah Penutup Harian}

Tumpukan sampah pada sistem controlled landfill ditutup oleh tanah penutup harian setiap 7 hari sekali. Sampah disebar sampai ketebalan sekitar $0,5 \mathrm{~m}$ kemudian digilas dengan alat berat sebanyak 5 kali gilasan sampai ketebalan $2,5 \mathrm{~m}$ kemudian ditutupi tanah penutup harian setebal $20 \mathrm{~cm}$. Lapisan berikutnya dilakukan hal yang sama, hingga mencapai ketebalan ketebalan $5 \mathrm{~m}$. Tinggi lapisan setinggi sekitar $5 \mathrm{~m}$ disebut sebagai 1 lift. Saat kondisi sampah sudah mencapai $5 \mathrm{~m}$, timbunan tersebut ditutupi oleh tanah penutup antara setebal $30 \mathrm{~cm}$. Tujuan ditutupnya sampah dengan tanah adalah untuk mencegah tersebarnya sampah, estetika, mencegah timbulnya bau sampah dll.

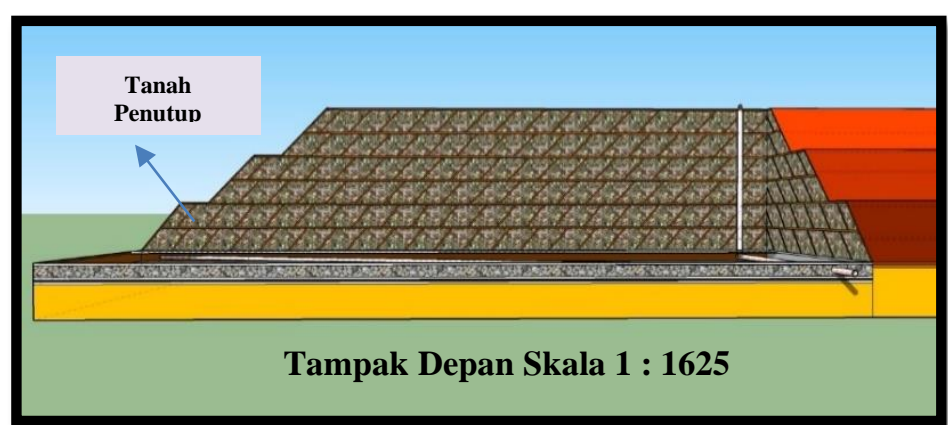

(a) 
ISSN 2460-691X

Nendia N.I. et al./JLK (2019) Vol. 2(1): 24-33

Jurnal Ilmiah

त LINGKUNGAN

KEBUMIAN

Pelestarian Fungsi Bumi dan Atmosfer

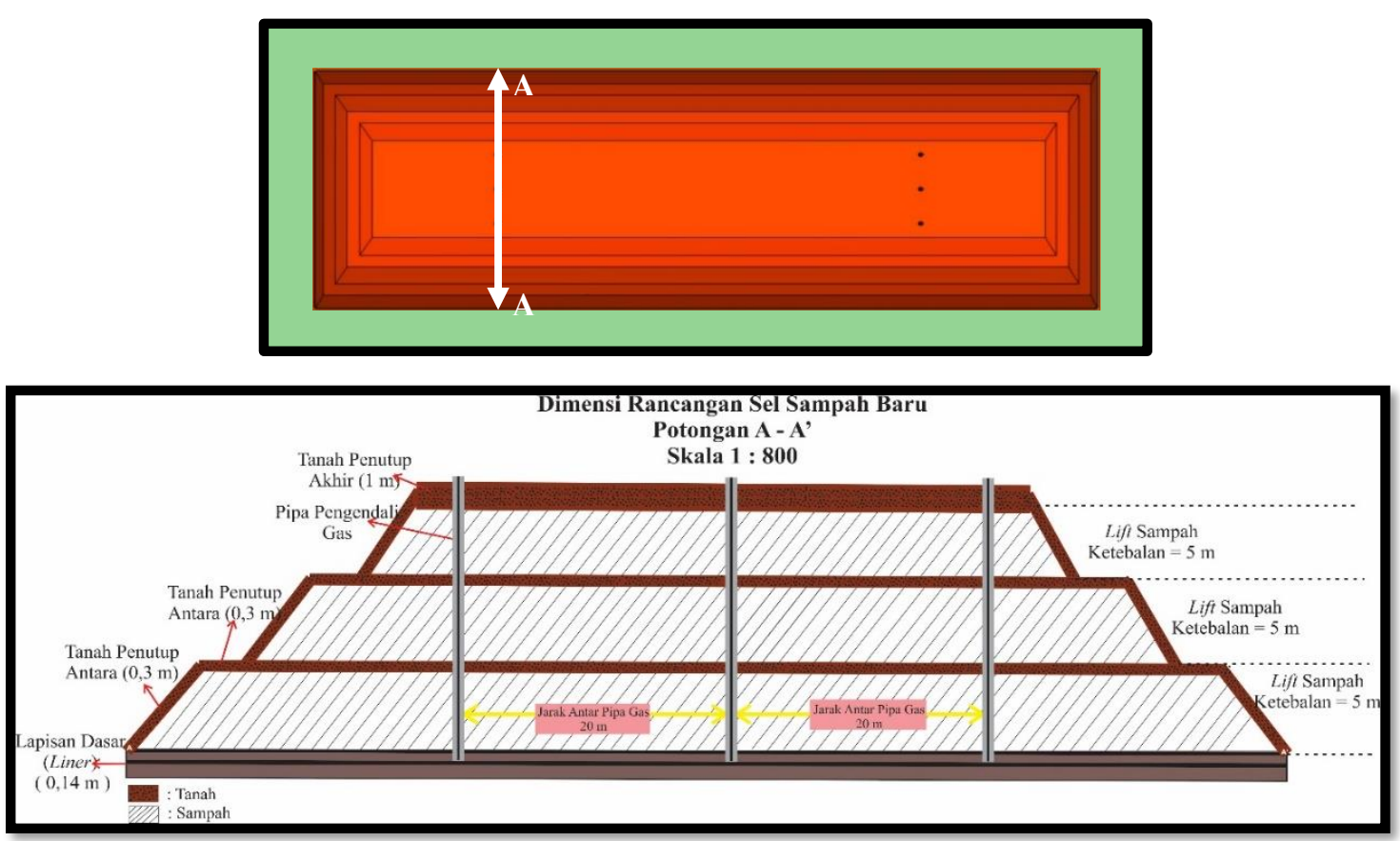

(b)

Gambar 7. Rancangan Sel Sampah Baru dengan Sistem Controlled Landfill

(a) Tampak Atas ; (b) Desain Gambar Potongan A-A'

Sumber: Penulis. 2019

\section{Sistem Pengendali Gas}

Kondisi TPA yang belum mempunyai unit sistem pengendali gas harus membuat atau merancang sistem pengendali gas baru, yang fungsinya mempunyai hubungan dengan jaringan pengumpul lindi. Konsentrasi gas metana pada udara ambien di TPA Sampah Kopi Luhur tergolong besar sehingga menghasilkan nilai indeks sensitivitas 1 (menunjukkan mempunyai bahaya besar untuk lingkungan). Pipa gas vertikal yang dibuat mempunyai diameter $50 \mathrm{~cm}$, berisi kerikil-kerikil berdiameter $4 \mathrm{~cm}$.

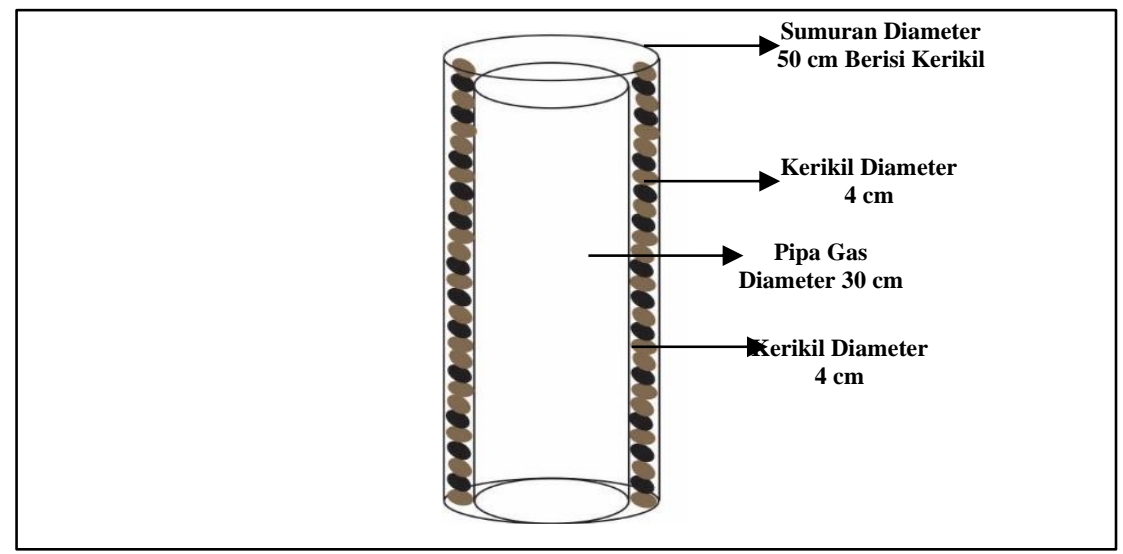

Gambar 8. Rancangan Pipa Pengendali Gas di TPA Sampah Kopi Luhur 


\section{KESIMPULAN}

1. Kandungan sampah lama di TPA Sampah Kopi Luhur berdasarkan pengukuran di lapangan terdiri dari 9,09\% B3, 12,91\% biodagredable dan 58\% sampah plastik (non-biodegradable).

2. Area lahan urug baru yang dirancang mempunyai panjang $198 \mathrm{~m}$ dan lebar $65 \mathrm{~m}$

3. Proses pengurugan dengan sistem controlled landfill yaitu sampah disebar dan dipadatkan sampai ketebalan 2,5 m kemudian ditutupi tanah penutup harian (dilakukan setiap 7 hari sekali). Saat ketebalan sampah mencapai $5 \mathrm{~m}$, sampah tersebut ditutup dengan tanah penutup antara setebal 30 $\mathrm{cm}$. Hal tersebut dilakukan berulang sampai ketinggian maksimum $15 \mathrm{~m}$

4. Proses rehabilitasi TPA dilengkapi dengan fasilitas perlindungan lingkungan seperti lapisan dasar, sistem drainase, jaringan pengumpul lindi dan sistem pengendali gas

5. Umur pakai lahan urug baru dengan sistem controlled landfill adalah 6,6 tahun

\section{DAFTAR PUSTAKA}

Andhika, R. (2015). Pengaruh Paparan $\mathrm{CH}_{4}$ dan $\mathrm{H}_{2} \mathrm{~S}$ Terhadap Keluhan Gangguan Pernapasan Pemulung di TPA Mrican Kabupaten Ponorogo. Ponorogo : Universitas Darussalam.

Damanhuri, E \& Padmi, T. (2016). Pengelolaan Sampah Terpadu. Bandung : Institut Teknologi Bandung

Damanhuri, E. (2006). Pedoman Pengoperasian dan Pemeliharaan Tempat Pembuangan Akhir (TPA) Sistem Controlled Landfill dan Sanitary Landfill. Bandung : Teknik Lingkungan ITB.

Diseminasi dan Sosialisasi Keteknikan Bidang PLP Materi Bidang Sampah:Penyusunan Pemrosesan Akhir Sampah. Kementrian Pekerjaan Umum Direktorat Jenderal Cipta Karya Direktorat Pengembangan Penyehatan Lingkungan Permukiman Tahun (2013).

Isni, N. N. (2019). Evaluasi Tempat Pemrosesan Akhir (TPA) Sampah Kopi Luhur Berdasarkan Penilaian Indeks Risiko Lingkungan di Dusun Sumur Wuni, Kelurahan Argasunya, Kecamatan Harjamukti, Kota Cirebon, Provinsi Jawa Barat. Skripsi. Tidak Diterbitkan. Fakultas Teknologi Mineral. Teknik Lingkungan UPN "Veteran" Yogyakarta : Yogyakarta.

Peraturan Menteri Pekerjaan Umum Republik Indonesia Nomor 03/PRT/2013 tentang Penyelenggaraan Prasarana dan Sarana Persampahan dalam Penanganan Sampah Rumah Tangga dan Sampah Sejenis Sampah Rumah Tangga.

Usman, S. (2010). Pengolahan Air Limbah Sampah (Lindi) dari Tempat Pembuangan Akhir Sampah (TPA) Menggunakan Metoda Constructed Wetland. Tanjungkarang : Jurusan Kesehatan Lingkungan Poltekkes Kemenkes Tanjungkarang. 